\title{
Case Report: Health System Response and Management: Lessons Learned From Iran's 2019 Floods
}

\author{
Hamidreza Khankeh", ${ }^{1,}$, Pirhossein Kolivand ${ }^{3}$, Shokoufeh Ahmadi ${ }^{1}$, Babak Farzinnia ${ }^{4}$, Jafar Bazyar ${ }^{*}$ \\ 1. Research Center for Emergency and Disaster Health, University of Social Welfare and Rehabilitation Sciences, Tehran, Iran. \\ 2. Department of Clinical Science and Education, Karolinska Institute, Stockholm, Sweden. \\ 3. Organization of Behavior Management, Payame Noor University, Tehran, Iran. \\ 4. Research Center for Environmental Pollutants, Qom University of Medical Sciences, Qom, Iran
}

\begin{tabular}{|l|l|l|l}
\hline $\begin{array}{c}\text { Use your device toscan } \\
\text { and readthe article online }\end{array}$ & $\begin{array}{l}\text { Cftation Khankeh HR, Kolivand P, Ahmadi Sh, Farzinnia B, Bazyar J. Health System Response and Management: Lessons } \\
\text { Learned From Iran's 2019 Floods. Health in Emergencies and Disasters Quarterly. 2020; 5(4):227-236. http://dx.doi.org/10.32598/ } \\
\text { hdq.5.4.355.1 }\end{array}$ \\
doi: : http://dx.doi.org/10.32598/hdq.5.4.355.1
\end{tabular}

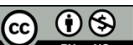

Article info:

Received: 28 Feb 2020

Accepted: 16 Jun 2020

Available Online: 01 Jul 2020

\section{Keywords:}

Disaster, Emergency, Incident, Flood, Health, Climate change

\begin{abstract}
A B STRACT
Background: While the main concern of Iran has been the risk of drought, and the Iranian authorities are always trying to find the solutions and prepare projects for the supply of their citizens' water, this country suddenly experienced a massive flood that affected more than 31 provinces in 2019. This study was conducted to extract lessons learned from the health system response and management of Iran in the 2019 floods.

Materials and Methods: This report was designed and implemented using a multi-method model with both quantitative and qualitative methods.

Results: In this year, more than 42 million Iranian citizens were affected by the flood. The medical centers provided services for more than 1137000 people. Also, 85 people died and 19 outbreaks were identified in the flooded areas.

Conclusion: Preventing flood victims to have access to humanitarian help and illegal measures concerning international cooperation seems to be immoral and at least sanctions should not be included in helping people in disasters, especially the health system is considered. Unfortunately, there is still a lack of ability to predict climate change, and it is necessary to focus on this issue. the "all-hazards" approach should be taken into consideration for the effective management of these incidents.
\end{abstract}

\section{Introduction}

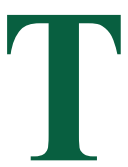

he repeatability and severity of floods will increase as a result of climate change [1]. Floods have affected human populations more than any other natural hazards in the $21^{\text {st }}$ century, so that during 18 years from 2000, floods affected more than 121 million people, and ranked first in terms of population index affected, and third in terms of mortality rates with more than 8000 deaths among the total natural hazards in the world [2]. In Iran, the climatic and geographical conditions are such that almost every year there is a flood causing a lot of damages. Although Iran has a dry climate, more than half of its area is affected by floods [3].

It has been estimated that more than 170000 people on average are exposed to floods each year, causing 242

\section{* Corresponding Author:}

Jafar Bazyar, PhD.

Address: Research Center for Emergency and Disaster Health, University of Social Welfare and Rehabilitation Sciences, Tehran, Iran.

E-mail: bazyarjafar@gmail.com 
death in this country [4]. Various studies have shown that even a local and limited flood may have a significant impact on the physical and mental health of humans. Previous studies have shown that after flooding, the occurrence rate of a variety of diseases in people, whose homes have been flooded, was 4 times higher than people whose homes have not been flooded [5]. Because the main concern of Iran has been the risk of drought, and the Iranian authorities are always trying to find solutions and projects for the supply of their citizens' water, this country suddenly experienced a massive flood of about 90 billion $\mathrm{m} 3$ of water involving more than 30 provinces of the country in 2019.

Of this amount, about 40 billion $\mathrm{m} 3$ of water were stored behind the dams and the rest affected the normal lives of people. Therefore, the health system was forced to provide sustainable health services for about 42 million people. The most important demand for people in disasters is health and health preparedness is an essential factor in preventing, managing, and reducing deaths and injuries [6]. Although each flood is unique in terms of its demographic and economic characteristic s, there have still many common features and sufficient knowledge about the causes of death and different kinds of flood damage and disease helps to ensure the effectiveness of the health system measures in managing these disasters [7].

In this regard, in the current study, we review the floods occurred between March 17, 2019, to April 22, 2019, which lasted for 37 days, occurred in more than 30 Iranian provinces and left more than one million injuries and death [8]. Moreover, the strengths and weaknesses of the health system's response to the flood effects and key suggestions for future actions are highlighted. Studying these issues can help to provide a basis for reviewing and resolving the challenges and problems in planning and services and pave the way for improving the past services and the preparedness of the health system in responding and managing future floods. On the other hand, the analysis of the unique health system experience in one of the largest floods of the last century could provide valuable information for other countries in managing disaster risk. Therefore, this study was designed and conducted to extract lessons learned from the health system response and management of Iran in the 2019 floods.

\section{Materials and Methods}

This report was designe $\mathrm{d}$ and implemented using a multi-method model [9]. The information needed for this study is based on the reports provided by the Treatment Deputy, the Disaster Risk Reduction Unit of the Depart- ment of Health, the National Emergency Department, the Iran Food and Drug Administration, the Iranian Blood Transfusion Organization, and the Emergency Operations Center (EOC) of the Department of Health. So, the official reference of the information provided in this research is the Ministry of Health and Medical Education as the most reliable source for receiving and confirming information on emergencies and disasters in Iran's health system.

Besides, a focused group interview with the presence of experts affiliated with the directing centers of the affected universities and also individual interviews with managers and contributors to recent flood management were conducted, fi n ally, all available documentation was also examined. Then, the collected information was extracted through the qualitative content analysis of all documents, reports, and interviews, and the lessons learned. Finally, the results of the content analysis, including the strengths, expandable points, and suggestions were classified and presented [10]. A qualitative content analysis method using in-depth semi-structured interviews and focus groups was used to collect and analyze the study data. Trustworthiness was applied with the Lincoln and Guba approach and the obtained data were analyzed with Graneheim and Lundman method [11]. After transcription of all interviews, codes, subcategories, and categories were extracted via open coding through line by line reading of the text. Then, the categories were identified by a constant comparison process.

The four criteria strategies recommended by Lincoln and Guba [12] for the trustworthiness of the data include credibility, de p endability, confirmability, and transferability. To increase data creditability, the researcher engaged with data and the environment for months in the study period. Besides, triangulation involves the use of multiple and different methods, investigators, sources, and theories to obtain relevant data. We also used member check, expert check, and peer check to ensure the credibility of the results. Dependability was established using an audit trail, a code-recode strategy, and peer examination. To ensure confirmability, we used the background and personal interest of the researcher on the subject. To improve transferability, the demographics of the participants and the topic of interest were described in detail to allow the reader to decide about how to use the results.

\section{Hazard description}

Because of the heavy rainfalls and melting of ice in the mountainous areas and based on meteorological forecasts that took place from March 17, 2019, to April 22, 2019 , floods occurred in vast areas of the country [13] 
(Table 1). The flooding process was initiated on March 17,2019 , due to heavy rainfall in the northern and northeastern provinces of the country, especially in the provinces of Golestan, Mazandaran, and Khorasan, which left economic and financial losses. According to the reports, about $300 \mathrm{~mm}$ of rainfall occurred in 2 days - equal to the average annual precipitation of the Golestan Province- and in other areas of these provinces, about 50\%$70 \%$ of the total annual rainfall occurred only in less than 5 days, which was unprecedented in at least 70 years ago and according to meteorological surveys, such floods in these areas have had a returned period of 100 years.

From March 25, 2019, to March 29, 2019, another wave of rain began in northern, southern, and western Iran, causing damages in 25 provinces. The next wave, which began on March 31 in other parts of the country, especially in the western regions, placed at least 23 provinces at warning status. According to the latest reports from the Emergency Operations Centers (EOC), health services throughout the country continued after this period in 10 provinces such as Ilam, Golestan, Mazandaran, Khorasan Razavi, Sistan \& Baluchestan, Lorestan, and Khuzestan. In addition, other provinces were assigned a "warning status", so that if nec- essary, different health teams can be sent to the areas damaged by floods, landslides, and so forth.

\section{Results}

Health system interventions at the warning and pre-disaster stage

The Ministry of Health and Medical Education, based on the 3 early alerts and warnings of the Meteorological Organization in March 2019, as well as 12 alerts and warnings issued by the Organization in April 2019, alerted all the universities of medical sciences throughout the country to accelerate the response to potential flood victims and even the snow blizzards and others incidents related to the above warnings. Then, all EOCs (Emergency Operation Center) and MCMCs (Medical Care Monitoring Center) were activated.

Moreover, to accelerate the medical services, all rapid response teams got fully prepared in different parts of the health system to provide emergency care services in the shortest time. These necessary health services included the transfer of injured people, health surveillance of communicable and non-communicable diseases, and

Table 1. Areas involved with flood and duration of services

\begin{tabular}{ccccccc}
\hline $\begin{array}{c}\text { Number of Prov- } \\
\text { inces Involved }\end{array}$ & $\begin{array}{c}\text { Number of Cit- } \\
\text { ies Involved }\end{array}$ & $\begin{array}{c}\text { Number of } \\
\text { Towns and Vil- } \\
\text { lages Involved }\end{array}$ & $\begin{array}{c}\text { Mountain Land- } \\
\text { slide (province) }\end{array}$ & $\begin{array}{c}\text { The Occurrence } \\
\text { of Storms (Prov- } \\
\text { ince) }\end{array}$ & $\begin{array}{c}\text { Snow Blizzard } \\
\text { (Province) }\end{array}$ & $\begin{array}{c}\text { Duration of } \\
\text { Health Services } \\
\text { (Day) }\end{array}$ \\
\hline 31 & 347 & 3856 & 6 & 6 & 20 & 37 \\
\hline & & & & $\begin{array}{c}\text { lileath in } \\
\text { Emergencies and Dlisasters (Oluarterly }\end{array}$ \\
\hline
\end{tabular}

Table 2. Provision of services to the injured patients admitted to health centers in the affected provinces, including elective patients and flood victims from March 19, 2019, to April 22, 2019

\begin{tabular}{cccccccc}
\hline $\begin{array}{c}\text { Services Provided by Fixed and } \\
\text { Mobile Medical Centers }\end{array}$ & \multicolumn{2}{c}{ Prehospital Emergency Services } & & Air Emergency Services \\
\hline $\begin{array}{c}\text { Total Number of } \\
\text { Admissions }\end{array}$ & $\begin{array}{c}\text { Number of } \\
\text { Admitted } \\
\text { Patients }\end{array}$ & $\begin{array}{c}\text { Number of } \\
\text { Admissions }\end{array}$ & $\begin{array}{c}\text { Number } \\
\text { of Patients } \\
\text { Deployed }\end{array}$ & $\begin{array}{c}\text { Number of } \\
\text { Treatments in } \\
\text { Place }\end{array}$ & $\begin{array}{c}\text { Total Flight } \\
\text { Hours }\end{array}$ & $\begin{array}{c}\text { Number } \\
\text { of Patients } \\
\text { Transferred } \\
\text { to Safe } \\
\text { Places }\end{array}$ & $\begin{array}{c}\text { Number } \\
\text { of Patients } \\
\text { Transferred } \\
\text { to Medical } \\
\text { Centers }\end{array}$ \\
\hline 1130775 & 174215 & 3285 & 1411 & 1874 & 330 & 2850 & 748 \\
\hline
\end{tabular}

Table 3. Flood deaths

\begin{tabular}{|c|c|c|c|c|c|c|c|}
\hline \multirow{2}{*}{$\begin{array}{l}\text { Total } \\
\text { Death }\end{array}$} & \multicolumn{5}{|c|}{ Cause of Death } & \multicolumn{2}{|c|}{ Gender (\%) } \\
\hline & Drowning & Thunderstorm & Landslide & $\begin{array}{l}\text { Mountain } \\
\text { Landslide }\end{array}$ & Electrocution & Male & Female \\
\hline 85 & 73 & 4 & 2 & 3 & 3 & $67 \%$ & $33 \%$ \\
\hline
\end{tabular}


Table 4. Estimating damages to the health system infrastructure

\begin{tabular}{cccc}
\hline $\begin{array}{c}\text { Prehospital Damage } \\
\text { (US Dollar) }\end{array}$ & $\begin{array}{c}\text { Hospital Damage } \\
\text { (US Dollar) }\end{array}$ & $\begin{array}{c}\text { Health Damage } \\
\text { (US Dollar) }\end{array}$ & $\begin{array}{c}\text { Total Health System Damages } \\
\text { (US Dollar) }\end{array}$ \\
\hline 1394815 & 36599259 & 15309289 & 53303363 \\
\hline
\end{tabular}

IHlealth in

Emergencies and |D]isasters [Oluarterly

even provide services to the patients with non-contagious and peculiar diseases.

\section{Hazard consequences}

The most important consequences of emergencies and disasters are seen in indicators such as the number of deaths, injuries, affected populations, and economic losses. As for the risk of floods, economic losses are far more than physical injuries and damages.

Injured individuals, patients, and affected populations

In this incident, more than 42 million Iranian citizens were affected by the flood. The medical centers, fixed and mobile clinics, pre-hospital emergency departments, and air emergency departments were fully prepared for the reception, treatment, and transfer of the injured patients during this time and provided services for more than 1137000 people (Table 2).

\section{Mortality}

A total of 85 people died in the incident [14]. Of whom, $67 \%$ were females and $33 \%$ were females. The youngest victim was 3 , and the oldest was 83 years old (Table 3 ).

\section{Outbreaks and Epidemics of Diseases}

A sampling of 3923 suspicious cases of contagious diseases needing immediate report and 2731 suspected cases of contagious diseases rejection was done. There were 2856 cases of animal bites. A total of 19 outbreaks were identified in the flooded areas, all of which were small, with fewer than 10 people infected in each of these floods. Because of the strong and extensive structure of the health system in the country, all cases were quickly identified and controlled in the shortest time.

\section{Economic damage to health infrastructure}

Of the total number of 7371 healthcare infrastructures, 943 infrastructures were damaged. The initial damage estimate to the infrastructure of the health system was worth 53303363 US dollars (Table 4).
The health system strengths, and improvable points in response and management of floods

There were many strengths and improvable points in response and management of Iran's 2019 floods that are listed here (Table 5).

\section{Key messages and suggestions for future actions}

Given the limited capacity of the Crisis Management Organization for the comprehensive disaster management and coordination of emergencies and disasters, and the organization's focus on the response to disasters, there is a need to review the organizational status, resources, and approaches with a greater focus on the prevention and risk reduction.

- Attention should be paid to the resilience and comprehensive management of disaster risk based on scientific evidence and international recommendations.

- It is necessary to compile indicators for assessing the quality and quantity of response operations based on comprehensive indicators and indigenous tools.

- Protocols should be prepared related to the needs of vulnerable groups during floods.

- Protocols should be developed for dealing with chemicals and toxins events in flood.

Protocols must be formulated for relief equipment and personal protection of the relief workers in flood.

- Assessment teams should be established at the national level and universities.

- It is necessary to activate the GIS team (or similar collection of information processing programs) to abreast the affected areas in Emergency Operations Centers.

- A guideline should be developed for health injury assessment at universities. 
- Attention should be directed to the issues of risk communication and rapid alert in disasters, especially flood incidents.

- Managers should be trained to respond to flood relief needs based on the National Response Framework and the NRF-Leveling program.

- It is necessary to develop a preparedness plan for the health system for flood prevention and continuity of service provision.

- Public safety culture must be promoted.

- Proper mechanisms must be designed for establishing a link between systems related to disaster risk management, such as insurance with a level of safety related to citizen privacy, accountability, and public responsibility in safety.

- Database integration and exchange of health information are necessary by determining the level of access.

- Secondary data sources, including satellite imagery, maps of relevant internet sites, and, of course, field observations must be used to estimate the extent and severity of the damages and the sectors affected.

- Attention must be paid to the comprehensive development after the incident and reducing the vulnerability of health infrastructure.

- Guidelines should be formulated for the presence of volunteers in a focused, targeted, and adequate manner.

- The role of universities must be highlighted in managing and preventing incidents, in particular, in developing a comprehensive map for city and province risks.

- Guidelines must be formulated for international assistance and adjusting the requirements based on any incident in advance.

- Relief workers must be taught to confront epidemics of contagious and infectious diseases for active disease screening.

- Different aspects and health outcomes of climate change must be examined.

- Alternatives (rail and air routes) should be developed to road assistance.
- The presence of psychological support teams must be encouraged in the affected areas.

- Credit must be allocated to create sustainable health and medical infrastructure with permanent heating and cooling systems for damaged areas.

- The Emergency Operations Centers must be equipped to receive aerial images of unmanned aerial vehicles and other remote sensing systems.

- The protocol should be formulated for sending and delivery of drugs to patients and visitors systematically.

- An autonomous regional communications network must be established through cell phones for the health system using services provided by operators located in the region and specifically for the exchange of data and information.

- Proper and timely information from monitoring organizations, then transmission and understanding of these alerts, along with proper feedback from the highest ministry official to the lowest level in the health services (including health staff in the villages) in all areas of the health system can be effective in reducing flood effects.

- The purchase of equipment, including helicopters (especially night vision helicopters) and boats will be effective in flood management for the daily transfer of items, equipment, and the deployment of health teams.

- The use of people with specialized disaster management knowledge at managerial posts, especially at the university level, is effective in understanding risk management processes.

- People-centered risk management and increased knowledge of people and community involvement in risk and disaster risk management can be very effective in disaster management, especially flood management. It is recommended that this issue be addressed by crisis authorities particularly in the field of health.

- Attention should be paid to the role of national media and virtual networks, especially the strengthening of health programs in IRIB, which will be useful in information and health promotion education.

- The use of insurance and the need to insure houses, property, and assets against disasters, especially in highrisk areas of the flood, can promote the mental health of flood victims and reduce mental conflicts. 
Table 5. Strengths, and improvable points in response and management of Iran's 2019 floods

Strong Points
Improving the performance of health macro-management in the flood
compared to the past, with the focus of the Emergency and Emergency
Operations Center (EOC)
Integrated Health Services Management at the EOC of the Ministry of
Health and the activation of the National Response Framework (NRF) from
the national level to the local level. It should be clarified that the frame-
work is designed by the Emergency Agency and communicated to the
entire country's universities and provided with the necessary training. The
activity of this system is based on the level of the incident.

The possibility of supporting medical universities and using specialized and competent personnel in the field of healthcare using national resources and the division of decuple poles

An increase of approximately 3 times the force and specialized equipment in the health realm in the affected areas using existing resources based on the National Emergency Operation plan

Focus on collecting and sending facilities from the Ministry of Health headquarters to the affected areas based on the unit management pattern

Working closely with partner organizations, especially the armed forces, mobilizing the medical community with the focus on the healthcare team in unexpected events

Activation of the disaster management area at the EOC of the Ministry of Health (the presence of qualified and trained personnel in the field of disaster management in the Ministry of Health and Medical Education), and the participation of all department operations centers

Proper coordination of the minister of health, the president of the emergency department of the country, and all the affiliated health system units of the Emergency Management Organization for the macro-management of health in floods

Determining the level of the disaster daily and improving it according to the information received from the field following the national guidelines

Activation of the healthcare team and subcommittees as the policy arm and coordination of the health system through the specialized decision making and continuous meetings

Cooperation of the Ministry of Health with the funding of medical universities in addition to regular budgets to provide the necessary resources for a comprehensive response to the flood

Equipment depot and management of specialized health personnel to provide resources and personnel for a long period (comprehensive management of health volunteers)

Documentation, centralized management of information, statistics, and reports from all departments and aggregation of reports by the Emergency Operations Center

Increasing the capacity of clinics located in the region (ICU beds, respiratory isolation, etc.) through mobile hospitals or dispatching surge capacity

\section{Improvable Points}

- The absence of a national flood warning and alert system

- The need for greater coordination with the national media (IRIB and the Ministry of Communications) to send warning and preventive messages

Lack of proper training programs for extreme floods

- No adequate explanation of the position of the EOC based on the National Response Framework (NRF) in the partner and supporting organizations

- Lack of unity of command in partner and supporting organizations

- The direct link between the deputies of universities and the deputies and head departments of the ministry

- The shortage of standard equipment for information

management and early warning systems in some of the Emergency Operations Centers

- Lack of experience and lack of standard tools for estimating the health system damages

- Lack of coordination between health centers, especially between academic and national centers

- Unrealistic requests for manpower and equipment by some universities

- Unnecessary requests by some universities during flood

The absence of a comprehensive crisis response management protocol in some small urban and rural areas

Lack of urgent flood relief equipment (boat, tractor, night vision helicopter ....)

Lack of some basic health facilities for mobile stations (bathroom and toilet)

Relocation of the injured patients locally and without coordination with Emergency Operations Centers

- Incomplete and unreliable communication methods

- Inappropriate status of mobile phone operators

- Disconnection of home telephones and the Internet

Lack of self-reliance of some of the expedited teams of the partner organizations (with no food, medicine, bed places, baths, etc.)

The absence of a comprehensive plan to declare the end of the critical situation using standard indicators and tools

Lack of a specific custodian for the unified information of the field and not prioritizing it for relief agencies

Lack of an operational plan concerning prior, after, and during flood actions for the partner and supporting health organization compatible with health program

Absence of regulatory formats and performance evaluation indicators following critical conditions 


\section{Strong Points}

Providing all needed drugs in the shortest time, including medications for specific diseases and predicting OTC drugs for distribution between ambulances and bus ambulances

Providing health items needed in the flooded areas with the help of manufacturing companies, including cellulosic products, detergents, and drinking water

Preparing and managing Disaster Medical Assistance Teams (DMAT) teams to support health services in the affected areas, based on the ongoing assessment of the health needs of the affected areas

Increasing the capacity for providing three times more services, that is, prehospital emergency medical services in the region in the shortest time based on regular programs and exercises

The prediction of prehospital specialist teams for medical interventions in the affected and remote areas

Provision of air ambulance services with the coordination and cooperation of partner and supporting organizations

Dispatching the environmental health and management teams to manage infectious diseases and nursing teams to control and monitor contagious diseases, drinking water, food preparation and distribution centers, mater nal and child health care services, and vulnerable groups with attention to accurate disease observation and health care contro

Active association with international organizations to use the capacities of these organizations to supply items that have not been available due to outrageous sanctions

Dispatching expert physicians such as anesthesiologists, infectious disease specialists, gynecologists, internists, emergency medicine with a detailed daily needs assessment

Active participation in the extensive and rapid disinfection of homes after the flood has subsided in the damaged areas

Having a program to deal with the influx of rodents, snakes, and insidious animals (animal bites) after the flood

Supervising the healthy burial of animal bodies

\section{Improvable Points}

Requesting specialized health personnel by some nonhealth managers

Establishing some mobile clinics without co-ordination with the EOC in the region by partner organizations and sponsors

The problems of returning to the place of residence or temporary residence, for the majority of patients and affected people after receiving medical treatment and discharging from the hospital due to the lack of rehabilitation program in emergencies and disasters

Unavailability of basic air transfer services during the night, rainfall, and winds with a speed of more than

30 knots and reduced vision due to lack of appropriate helicopters caused by sanctions

The impossibility of an initial assessment of modern technologies such as unmanned aerial vehicles

Not paying attention to the cultural aspects of providing people's needs, such as food and human dignity, in donating aid in some areas

Lack of suitable assistance vehicles for flood conditions due to sanctions

Non-coordination between some relief organizations

Weaknesses in the communication layers of partner organizations and supporters due to lack of satellite phones

Lack of awareness, and intervention of managers of some partner and supportive organizations in health risk management plan

The disaster management organization's weakness in the coordination and support of relief organizations

Lack of communication link between information systems of partner and supporting organizations of the health system, especially with the Emergency Operations Centers

Provision of mental health services in affected areas through active and extensive screening via the presence of trained mental health teams from the first moments

The dispersal of EMS with the national and local number of 115, which increased the relief coverage in the affected areas
Lack of flood-related logistic facilities for rapid assessment teams
Continuous communication and coordination with meteorological organizations and timely information
Unnecessary relocation of the forces and discharging them to the scene due to inaccuracies in the selection of designated provinces and based on the level of the incident by the partner and supporting organizations and their managers
Holding regular weekly meetings of the working group with the presence of representatives from partner and supporting organizations to enhance coordination
Lack of adherence and strict implementation of NRF in management layers 


\begin{tabular}{|c|c|}
\hline Strong Points & Improvable Points \\
\hline $\begin{array}{l}\text { EOC boarding activity in all affiliated universities and cities to coordinate } \\
\text { services }\end{array}$ & $\begin{array}{l}\text { The structural weakness of the crisis management orga- } \\
\text { nization, particularly in inter-sectoral coordination }\end{array}$ \\
\hline $\begin{array}{l}\text { Creating an Incident Command Post (ICP) at the nearest safe location of the } \\
\text { incident in all flood-affected areas }\end{array}$ & $\begin{array}{l}\text { - The absence of national data and data banks in the } \\
\text { field of risk assessment } \\
\text { - Lack of a data backup system in the partner and sup- } \\
\text { porting organizations } \\
\text { - Contradiction in the statistics of the deceased, injured, } \\
\text { and affected individuals in different organizations } \\
\text { - Lack of online information registration systems } \\
\text { - Lack of access to the necessary databases at the inci- } \\
\text { dent guidance and command centers } \\
\text { - Lack of regional maps after the incident, display of the } \\
\text { affected areas, and the form of crisis expansion } \\
\text { - Getting inappropriate information from the harsh } \\
\text { locations of the incident }\end{array}$ \\
\hline $\begin{array}{l}\text { Order of consolidation and unity of management by the president of Iran } \\
\text { to the interior minister }\end{array}$ & $\begin{array}{c}\text { - Low understanding of risk, and disaster risk percep- } \\
\text { tion of people } \\
\text { - Capturing and watching the flood without considering } \\
\text { its dangerous consequences }\end{array}$ \\
\hline $\begin{array}{l}\text { The removal of abusive regulations to accelerate the cooperation of all } \\
\text { institutions with the order of the president }\end{array}$ & $\begin{array}{c}\text { Endangering mental health after a flood (specific psy- } \\
\text { chological responses, such as violence) } \\
\text { - Unemployment and aggravation of psychological } \\
\text { problems }\end{array}$ \\
\hline $\begin{array}{l}\text { Strengthening the EOC role of the Ministry of Health as the focus of health } \\
\text { assistance }\end{array}$ & $\begin{array}{l}\text { Animal health problems and common diseases of } \\
\text { humans and animals after the flood }\end{array}$ \\
\hline $\begin{array}{l}\text { The existence of a systematic network for recording information by health } \\
\text { care providers and health system staff }\end{array}$ & $\begin{array}{l}\text { Lack of attention to the health aspects of insect use of } \\
\text { food and Endangering food security by destroying crops } \\
\text { by the invasion of locusts }\end{array}$ \\
\hline $\begin{array}{l}\text { More sensitivity to alerts made by people and authorities especially alerts } \\
\text { issued by health authorities }\end{array}$ & $\begin{array}{l}\text { The half-time recession of serving organizations during } \\
\text { the New year holidays }\end{array}$ \\
\hline $\begin{array}{l}\text { The sense of the reputation of serving the affected people by relief agen- } \\
\text { cies, in particular, the Emergency Department of the country }\end{array}$ & $\begin{array}{c}\text { Lack of attention to the position, function, and struc- } \\
\text { ture of the EOC in some of the partner and supporting } \\
\text { organizations }\end{array}$ \\
\hline $\begin{array}{l}\text { The relative domination of knowledge and experience in the field of } \\
\text { disaster management and the creation of a common language between } \\
\text { forces affecting health and enhancing coordination and joint operational } \\
\text { capability }\end{array}$ & $\begin{array}{l}\text { Lack of adequate measures for the establishment and } \\
\text { provision of services by some field hospitals }\end{array}$ \\
\hline $\begin{array}{l}\text { Use of the capacity of native directors and the participation of local and } \\
\text { regional NGOs }\end{array}$ & $\begin{array}{l}\text { Insufficient attention to the risk of landmine remained } \\
\text { from the imposed war during flood and rainfall }\end{array}$ \\
\hline \multicolumn{2}{|l|}{ The possibility of documenting actions in a timely and up-to-date manner } \\
\hline \multicolumn{2}{|l|}{$\begin{array}{l}\text { Paying attention to the prevalence of infectious diseases, in particular } \\
\text { hepatitis } A \text { and } E \text {, and diarrhea in flood-affected areas }\end{array}$} \\
\hline $\begin{array}{l}\text { Paying attention to the insurance against emergencies and disasters (all } \\
\text { of the houses based in Aq Qala, in Golestan Province, were insured by the } \\
\text { municipality against the flood) }\end{array}$ & \\
\hline
\end{tabular}

- Designing specific criteria for a more accurate estimation of damages to health infrastructure and health care costs is recommended.

- The university administrators and staff should be trained concerning identifying EOC concepts and practices.

- The level of specialized training of health managers and workers about disasters should be increased. 
- It is necessary to provide insurance of property and buildings, equipment, and infrastructure for health at all levels of health and safety for emergencies and disasters.

- It is obligatory to strengthen communication and backup layers.

- Internal and external coordination must be consolidated.

- EOC and MCMC must work closely and dispatching 115 to accelerate coordination.

- It is necessary to perform continuous risk assessment, formulating, and updating risk map.

- It is recommended to design a suitable telecommunication system, such as satellite mobile or alternative means, in all subsets of health centers.

- Online cameras could be installed at ambulances to quickly assess the incident by regional and national managers.

- The Aphrodite cars should be supplied at universities for traffic in harsh areas.

- Plans are necessary to motivate the recruitment of health personnel in disasters.

\section{Conclusion}

Although floods in a provincial and smaller scale have occurred in Iran in recent years, there has never been such a flood with this extension and severity in this area in 2019 , and the health system did not have the same experience of an incident of this magnitude. One of the challenges of the health system in managing this incident was the lack of equipment (due to sanctions) needed by the health system to provide emergency services to people. Preventing flood victims from accessing humanitarian aids and illegal measures concerning international cooperation in reaching these aids seems to be immoral and at least sanctions should not be implemented in helping people in incidents, especially the health system.

Unfortunately, there is still a lack of ability to predict climate change, and it is necessary to focus on this issue so that the effective management of these events could be done better. Therefore, the "all-hazards" approach, and the risks associated with climate change should be taken into consideration. It is also recommended that similar studies, in particular cohort studies, be carried out to find long-term health outcomes due to such incidents and to modify and review our health-related programs. Besides, the need to study the social and cultural aspects of incidents, people's unwillingness to leave their homes and live in camps is quite tangible.

\section{Ethical Considerations}

\section{Compliance with ethical guidelines}

This research was approved by the Ethics Committee of the University of Social Welfare and Rehabilitation Sciences.

Funding

This research did not receive any grant from funding agencies in the public, commercial, or non-profit sectors.

\section{Authors' contributions}

Conceptualization, study design: Hamid Reza Khankeh, Jafar Bazyar, and Shokoufeh Ahmadi; Data analysis, data interpretation: Hamid Reza Khankeh, Jafar Bazyar; Writing the manuscript: Jafar Bazyar, Shokoufeh Ahmadi. Revision of the paper: Jafar Bazyar. Collection of data, approval of the paper: All authors.

\section{Conflict of interest}

The authors declared no conflict of interests.

\section{References}

[1] Schumann GJ-P, Bates PD, Neal JC, Andreadis KM. Technology: Fight floods on a global scale. Nature. 2014; 507(7491):169. [DOI:10.1038/507169e] [PMID]

[2] Lanes J.R., Vos F., Below R., Guha-Sapir D. Annual Disaster Statistical Review: Numbers and Trends. Brussels: CRED. 2009; Available from: http:/ / www.emdat.be

[3] Rahmati O, Zeinivand H, Besharat M. Flood hazard zoning in Yasooj region, Iran, using GIS and multi-criteria decision analysis. Geomatics, Natural Hazards and Risk. 2016; 7(3):1000-17. [DOI:10.1080/19475705.2015.1045043]

[4] Arabameri A, Rezaei K, Cerdà A, Conoscenti C, Kalantari Z. A comparison of statistical methods and multi-criteria decision making to map flood hazard susceptibility in Northern Iran. Science of the Total Environment. 2019; 660:443-58. [DOI:10.1016/j.scitotenv.2019.01.021] [PMID]

[5] Khan MRH. Satellite Based Predictability of Water Sensitive Infectious Diseases [PhD dissertation]. Morgantown: West Virginia University; 2018. 
[6] Paterson DL, Wright H, Harris PN. Health risks of flood disasters. Clinical Infectious Diseases. 2018; 67(9):1450-4. [DOI:10.1093/cid/ciy227] [PMID]

[7] Du W, FitzGerald GJ, Clark M, Hou XY. Health impacts of floods. Prehospital and Disaster Medicine. 2010; 25(3):265-72. [DOI:10.1017/S1049023X00008141] [PMID]

[8] Yadollahie M. The flood in Iran: A consequence of the global warming? The International Journal of Occupational and Environmental Medicine. 2019; 10(2):54-6. [DOI:10.15171/ ijoem.2019.1681] [PMID] [PMCID]

[9] Stake RE. The art of case study research. California: Sage; 1995. https://books.google.ro/books/about/The_Art_of Case_Study_Research.html?id=ApGdBx76b9kC\&redir_ esc $=y$

[10] Sharan MB. Qualitative research and case study applications in education. Revised and expanded from "Case study research in education". Hoboken: Wiley; 1998. https:/ / books. google.ro/books?id=kYMtQgAACAAJ\&dq=Qualitative + Re search+and+Case+Study+Applications+in+Education.+Revi sed+and+Expanded + from $+\% 22$ Case + Study + Research + in $+E$ ducation.\&hl=en\&sa $=X \& v e d=2 a h U K E w i N 4 I v 3 q 6 f t A h V v x 4 s$ KHWNJAxUQ6AEwAHoECAIQAg

[11] Graneheim UH, Lundman B. Qualitative content analysis in nursing research: Concepts, procedures and measures to achieve trustworthiness. Nurse Education Today. 2004; 24(2):105-12. [DOI:10.1016/j.nedt.2003.10.001] [PMID]

[12] Guba EG. Criteria for assessing the trustworthiness of naturalistic inquiries. ECTJ. 1981; 29(2):75. https://link.springer. com/article/10.1007/BF02766777

[13] Peyravi M, Marzaleh MA. Celebrities' effective presence during the large flood in Iran in 2019. Prehospital and Disaster Medicine. 2019; 34(6):681-2. [DOI:10.1017/ S1049023X1900503X] [PMID]

[14] Iranian Legal Medicine Organization (ILMO). 2019 [cited April 14, 2019]. Available from: http://www.lmo.ir. 